\title{
Carcinogenic Anthraquinone
}

National Cancer Institute

\section{Source}

National Cancer Institute. Carcinogenic Anthraquinone. NCI Thesaurus. Code C45177.

A compound that increases the risk of human cancer and is mainly used in the manufacture of dyes. These compounds consist of an anthracene ring that contains two ketone moieties in any position and can be substituted in any position except on the ketone groups. ( $\mathrm{NCI05)}$ 